\title{
International Vocational Education and Training Research: An Introduction to the Special Issue
}

\author{
Michael Gessler*1, Sandra Bohlinger ${ }^{2}$, Olga Zlatkin-Troitschanskaia ${ }^{3}$ \\ ${ }^{1}$ University of Bremen, Institute Technology and Education, Am Fallturm 1, 28359 Bremen, \\ Germany \\ ${ }^{2}$ Dresden University of Technology, Institute of Vocational Education and Vocational Di- \\ dactics, Helmholtzstr. 10, 01069 Dresden, Germany \\ ${ }^{3}$ Johannes Gutenberg University Mainz, Chair of Business and Economics Education, Jakob- \\ Welder-Weg 9, 55128 Mainz, Germany
}

\begin{abstract}
The seven articles in this special issue represent a wide range of international comparative and review studies by international research teams from China, Germany, India, Russia, Switzerland and Mexico. The presented projects are part of the national program "Research on the Internationalisation of Vocational Education and Training", funded by the German Federal Ministry of Education and Research (BMBF).

An adapted version of Urie Bronfenbrenner's ecological systems theory forms the conceptual framework of the special issue. The four system levels (micro, meso, exo and macro) are addressed by one article each. The article on the microsystem level focuses on the intended and implemented curricula in a cross-country comparison of China and Russia. The article on the mesosystem level aims at the development of a quality management model for vocational education and training (VET) institutions in India. At the exolevel, the regional structures of the education and employment systems in Mexico, particularly the cooperation between schools and companies in the hotel industry, are investigated. At the macrosystem level, the social representation of non-academic labour in Mexico is examined in terms of cultural artefacts. Furthermore, three overarching review studies systematise relevant research developments and approaches. The topics of the three review studies are European VET policy, transfer of VET and VET research. The scope ranges from the development of a comparative research tool to a summary analysis of over 5,000 individual publications.
\end{abstract}

${ }^{\star}$ Corresponding author: mgessler@uni-bremen.de

ISSN: 2197-8646

https://www.ijrvet.net

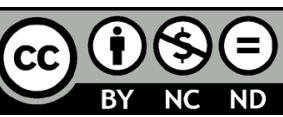


Given the broad scope and heterogeneity of the findings, a summative conclusion would hardly be appropriate. Nevertheless, with regard to the model of the 'triadic conception of purposes in comparative VET research' that represents a heuristic for describing the purposes of international VET research, we conclude with an emphasis on a need of more criticality. In this context, one finding can be pointed out as an example: One review study found that most studies (here, with reference to VET transfer) refer to the recipient country without a comparative perspective. Thus, there is a clear demand for more comparative research following a critical-reflective approach.

Keywords: Vocational Education and Training, Bronfenbrenner Model, Curriculum, Quality, Cooperation, Culture, Artefacts, Literature Review, European VET Policy, Transfer of VET, VET Research

\section{Introduction}

In contrast to general and higher education, which have (at least in parts) comparable curricula as well as comparable structures and institutions across countries and cultures, vocational education and training (VET) is often strongly regionally and nationally oriented, with diverse histories, self-conceptions, objectives, curricula, structures and practices. Internationally, VET is a parcelled field. This situation might explain the fact that no research network representing the academic discipline of VET has yet to be established at a truly international level. This could also be a reason why studies on VET are predominantly local, regional or national in their focus and scope. In comparison, other academic disciplines, such as medicine or economics, have a completely different and much more self-evident approach to the dimension of internationalisation. Since VET is linked to the world of work, however, this state of affairs is remarkable, as companies and labour markets are no longer primarily national but rather globally organised.

Whilst this noteworthy diversity poses a problem in developing a coherent international understanding and conceptualisation of VET, such heterogeneity has facilitated the emergence of an intensive form of VET cooperation in the field of development aid over the last 70 years. The predominantly asymmetrical cooperation usually occurs from North (donor) to South (recipient) or from industrialised to developing countries. Almost at the same time, a second type of predominantly symmetrical VET cooperation with a regional focus has emerged. An example of this type of cooperation is CINTERFOR in Uruguay, the Inter-American Centre for Knowledge Development in Vocational Training, founded by the International Labour Organisation in 1963. Besides others, one major difference characterises these two forms of cooperation: Whilst donor-oriented programmes usually work on the basis of temporary projects (with all the accompanying challenges, such as the lack of possibilities to 
work in a long-term and sustainable way as well as to accumulate knowledge, expertise and experience), the cooperation-oriented CINTERFOR approach is institutionalised, i.e., it offers the possibility of creating a regional network based on long-term cooperation, trust and mutual learning.

In VET cooperation, "Germany is currently the world's largest bilateral donor in the TVET sector. The German official development assistance (ODA) allocated for TVET (€ 231 million in 2017) even exceeded the corresponding contributions of the European Union and the World Bank" (Edel, 2020, p. 291). Whilst the German government has invested considerable resources in VET cooperation since the 1950's, interest in its effectiveness (detected by evaluation) and in gaining knowledge about the cause-effect relationships (detected by research) has been extremely limited.

The first selective evaluations did not begin until the 1990s (Stockmann, 1992). At the same time, VET cooperation had rapidly declined in the realm of political interest. Since the dissolution of the former VET Cooperation Department in the Ministry of Economic Development and Cooperation in the 1990s, VET cooperation has been considered only as a complementary instrument of economic development (Wolf, 2009). The reactivation of the commitment to VET cooperation after two decades can be attributed to two factors: (1) The financial, economic and social crises that started in 2007 and the international appreciation of the German VET system in this context ${ }^{1}$ and (2) the cooperation of the Ministry of Education and Research and the Ministry of Economic Development and Cooperation.

With such renewed commitment (thus leading to the actual status of 'leading bilateral donor'), VET research was declared and established in 2013 as the fifth guiding principle of the German international VET cooperation. The first four principles are as follows: (1) Joint responsibility of the state, industry and social partners; (2) learning in the work process; (3) acceptance of national occupational, training and examination standards; and (4) qualified training personnel in companies and vocational schools. The fifth principle includes institutionalised VET as well as labour market research and consultation on VET. Within the framework of international VET cooperation and with reference to these five principles, the German government thereby supported other countries in integrating elements of practiceoriented or apprenticeship-oriented VET into their respective systems (BMBF, 2013, 2019).

This new strategy employed by the German federal government has enabled a funding programme that promotes VET research at an international level. The programme "Research on the Internationalisation of Vocational Training", funded by the German Federal Ministry of Education and Research (BMBF), serves to strengthen and expand institutionalised VET research in Germany and abroad as an instrument for international VET cooperation. In particular, this funding programme aims to (1) sustainably strengthen the expertise of

1 For example, the Organization for Economic Cooperation and Development (OECD) noted that youth unemployment "certainly tends to be less often a problem (relative to adult unemployment) in countries like Germany with strong 'dual' apprenticeship systems." (OECD, 2010, p. 34). 
Introduction

universities and other research institutions in international VET research, (2) integrate this expertise more closely into the BMBF's international VET cooperation and make it accessible to foreign partners via established structures and, (3) support reform processes abroad in the direction of more practice-oriented initial and continuing VET (BMBF, 2017). The first funded projects in this programme began in 2019. The articles in this special issue originates from this research programme.

\section{Conceptual Framework}

To structure the contributions of this special issue, we use an adapted version of Urie Bronfenbrenner's ecological systems theory. Bronfenbrenner published the first systematic exposition of his theory in the 1970's and further refined and developed it in the following years (e.g. Bronfenbrenner, 1979; Bronfenbrenner \& Evans, 2000; Bronfenbrenner \& Morris, 2006). A central assumption of this theory is that a system consists of nested subsystems that are "each inside the next, like a set of Russian dolls. At the innermost level is the immediate setting containing the developing person. This can be the home, the classroom, or as often happens for research purposes-the laboratory or the testing room." (Bronfenbrenner, 1979, p. 3)

Bronfenbrenner (1979) calls this innermost level the "microsystem", which is "a pattern of activities, roles, and interpersonal relations experienced by the developing person in a given setting with particular physical and material characteristics" (p. 22). Within the microsystem, processes that are more or less effective can be distinguished in terms of development and learning. In effective processes, which are also called 'proximal processes', interactions "occur on a fairly regular basis over extended periods of time" (Bronfenbrenner \& Morris, 2006, p. 797). Learning settings are such proximal processes. Two types of outcomes can then be distinguished, namely, competence and dysfunction:

The term 'dysfunction' refers to the recurrent manifestation of difficulties on the part of the developing person in maintaining control and integration of behaviour across situations, whereas competence is defined as the demonstrated acquisition and further development of knowledge and skills-whether intellectual, physical, socioemotional, or a combination of them. (Bronfenbrenner \& Morris, 2006, p. 803).

Proximal processes enhance individual competences and reduce degrees of dysfunction. The next level, the mesosystem, is "a system of microsystems" (Bronfenbrenner, 1979, p. 25). A mesosystem is established based on interrelations between two or more immediate settings in which a person is an active participant. Participation in immediate settings (e.g. school and workplace) emphasises embeddedness and thus the concept of role (e.g. learner and worker), which is now visible in the diversity of institutional contexts. According to Bronfen- 
brenner (1979), "The developmental potential of participation in multiple settings will vary directly with the ease and extent of two-way communication between those settings" (p. 216).

The next level, the exosystem, consists of "settings that do not involve the developing person as an active participant but in which events occur that affect, or are affected by, what happens in that setting" (Bronfenbrenner, 1979, p. 237). Finally, the macrosystem contains the belief system or ideology of the given system levels (micro, meso and exo) and the integrational consistency. These generalised patterns that comprise the macrosystem represent the "manifestation of overarching patterns of ideology and organisation of the social institutions common to a particular culture or subculture" (Bronfenbrenner, 1979, p. 8).

The basic assumption of Bronfenbrenner's theory is that people develop whilst interacting with their environment. The approach, which has been transferred to German VET research (e.g. Kell, 1990), has been employed ever since (e.g. Zlatkin-Troitschanskaia, 2005; Lange, 2019). Here, we refer to Kell's interpretation from 1995. Kell distinguishes between work processes that are oriented towards the development and change of the environment and learning processes that are oriented towards the development and change of the self: "This separation and demarcation presupposes that there are (at least) two differently structured (organised) microsystems in which persons (can) develop differently: The workplace and the learning place. Both 'places' as specific environments stand in different (topologically nested) systems (environments)" (Kell, 1995, p. 376, translation by the authors).

Following Kell, teaching and learning arrangements can be classified as e.g. problem- and project-based learning, collaborative online learning and microlearning. Clustered arrangements then form the microsystem 'learning place', which can be located in a school or at a company. Workplaces are also never independently of their contexts but are elements of an organisation based on the division of labour. Moreover, workplaces are interconnected structurally (hierarchy) and procedurally (work process) and form the integrated microsystem of a company. These microsystems can be institutionally integrated into different mesosystems. For example, a microsystem 'learning place' can be located in a school or in a company. Hence, it is crucial that the conditions of the mesosystem influence the conditions of the microsystem without necessarily determining them. For example, a training centre in a company can be integrated into the production system or also define its identity at a distance from and in contrast to the production system.

Interactions also exist between the higher-level exosystem (e.g. the employment system) and the mesosystem. The Berufsprinzip (occupational principle) in Germany can serve as an example of these interactions. In particular, the orientation of VET in Germany at the mesosystem level towards the principle of Berufe (professions) is possible because the employment system at the exosystem is guided by this principle (Kell, 1995, pp. 376-382). Meanwhile, Streeck (2011) discussed other structuring principles of the employment system, such as tripartite cooperation or the social prestige of skilled workers. In the 'learning processes' pillar, 
the education system forms the relevant context of the corresponding institutions. Examples of these structuring principles include the permeability between vocational and academic education, the share of general education in vocational education or the equivalence of vocational education on the one hand and higher education on the other.

At this point, it becomes evident how strongly the macrosystem affects the structuring of the exosystem level (and the levels below): E.g., the German dual apprenticeship system is a structure (on the exosystem level) and a historically grown cultural pattern (on the macrosystem level). Hence, the continued functioning of the dual system is based on both the belief in this system and the established social structures. Thus, if the social structures are removed, such as when a German company establishes a subsidiary abroad, but the belief system is retained because e.g. the CEO in the subsidiary is a German, then there is a higher likelihood that the company will implement a dual system abroad, although it will be a modified one (Gessler, 2017).

Figure 1 shows the conceptual framework and the articles.

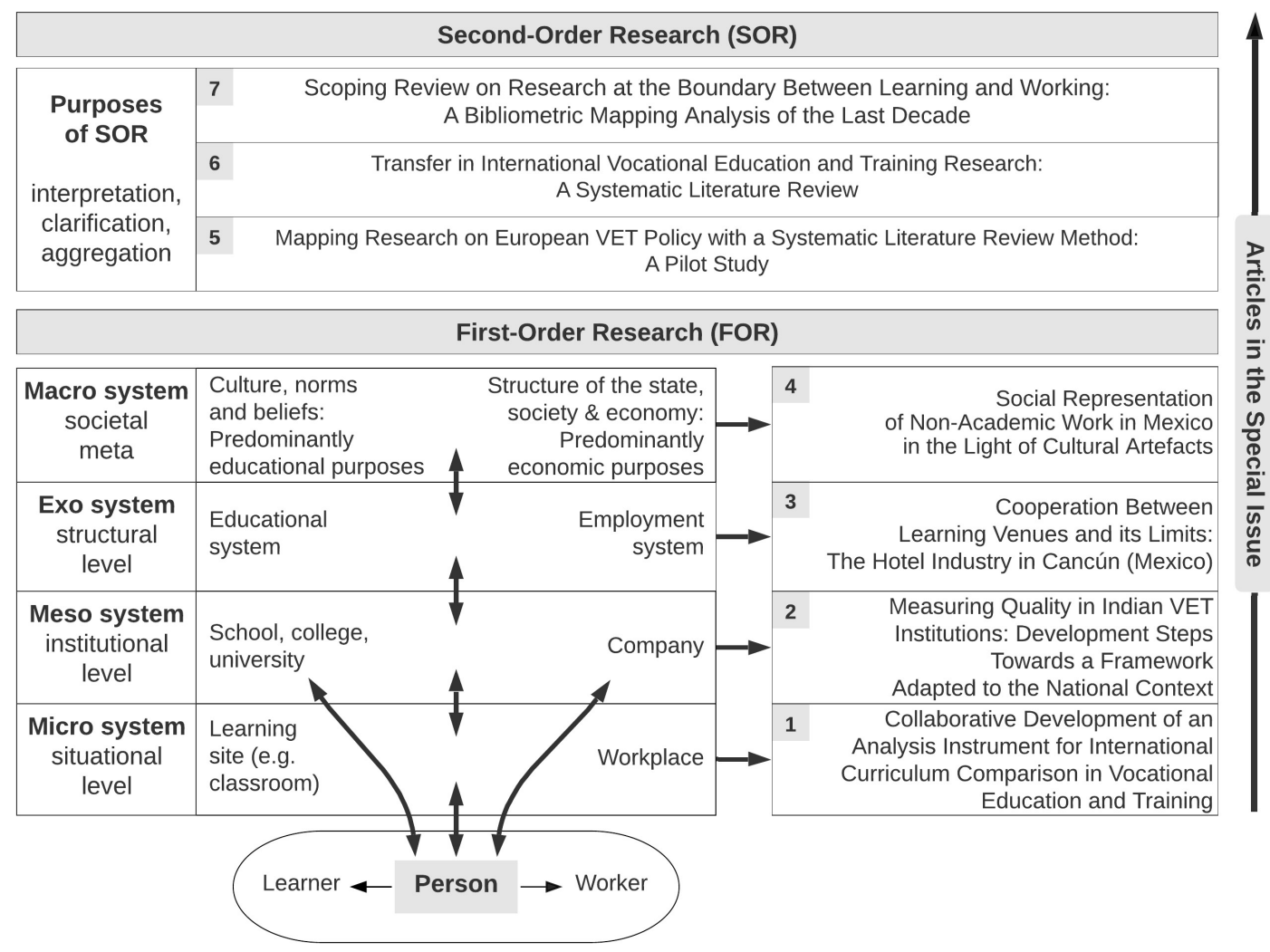

Figure 1: Structure and Articles of the Special Issue, based on Kell (1995, p. 377) 
On the basis of this outlined conceptual framework, we structured the first four articles. To this foundation based on first-order research, we added three articles focussed on secondorder research (literature reviews), with the goal of integrative knowledge interpretation, clarification and aggregation in a particular area of first-order research.

\section{The Articles of the Special Issue}

This section briefly introduces the seven contributions to the special issue, which will be published successively until the end of 2021. We begin with the first-order research and the four articles on the micro-, meso-, exo- and macrosystem levels.

\section{Microsystem Level}

International curriculum comparison in vocational education and training: A collaborative development of an analysis instrument by Pujun Chen, Anastasia Goncharova, Matthias Pilz, Dietmar Frommberger, Junmin Li, Olga Romanova and Yueru Lin:

The article focusses on the curriculum - a concept that is less well-defined than might be expected. Hence, the different meanings of a curriculum need to be distinguished from one another. In their analysis, the authors referred to a theoretical framework introduced by Van den Akker et al. (2010) and subsequently distinguished between an intended and an implemented curriculum. The intended curriculum can be seen as an element of the meso system level and thus acts as a mediator between the teaching/learning activities of the micro system level and the structures of the exosystem level (What should be learned and how should the output be measured?). In contrast, the implemented curriculum maps the actual teaching/ learning activities at the micro level (The 'curriculum in action' - What is taught and learned and what outputs are created?).

The (intended and implemented) curriculum approach can be thought of and implemented in different ways. The authors used a framing device introduced by Sturing et al. (2011), called the 'Revised Model of Comprehensive Competence-Based Vocational Education'. Using this framing device facilitated their theoretical-conceptual comparison of the curricula in Russia and China. Then, the stages 'Building the Analysis Framework' and 'dapting the Analysis Framework' (with the sub-steps Operationalisation of Categories Using Additional Literature Research, Data-Driven Adjustment of Categories, Reorganising Categories and Adding Categories Inductively) enabled the authors to trace step-by-step how the analytical tool to compare intended and implemented competence-based curricula in China and Russia was developed. 


\section{Mesosystem Level}

Measuring quality in Indian VET institutions: Development steps towards a framework adapted to the national context by Muthuveeran Ramasamy, Julia Regel, Harshil Sharma, Anjana Rajagopalan and Matthias Pilz:

The four major modes of the VET system in India consist of private training institutes, apprenticeship training, secondary, higher secondary schools and polytechnic colleges, and industrial training institutes (ITIs). The VET system in the country has grown significantly in the last 15 years. In particular, IITs have grown from less than 2,000 facilities in 2007 to almost 15,000 facilities in 2020. This rapid quantitative expansion, however, has been accompanied by negative feedback from the labour market (e.g. skills mismatch), thus leading to the problem of how the quality of VET institutions can be measured, controlled and improved. The authors, an Indian-German team of researchers, used a design-based research approach to investigate 44 mostly Asian and indigenous Indian quality models, of which 14 were selected for further analysis. Then, on the basis of over 400 indicators and criteria, the authors cross-referenced process dimensions (Input, Process, Output, Outcome) and content dimensions (Institutional Sphere and Context, Personnel, Educational Planning, Provision and Assessment, Learning and Teaching, Leadership and School Management, Industry Linkage and Learner Achievements), resulting in a matrix. In addition to model development, the model was adapted to the national context, a process that played a central role in the study. Culture and educational institutions are closely interwoven elements, which is why cultural conditions are particularly necessary when designing educational institutions. In this sense, cultural patterns ground normative decisions. As the society in India is characterised by high inequality and exclusion, the aspect of 'Inclusion, Access and Equity' has emerged as a central quality aspect of the model.

\section{Exosystem Level}

Cooperation between learning venues and its limits: The hotel industry in Cancún (Mexico) by Beke Vogelsang, Natascha Röhrer, Martina Fuchs and Matthias Pilz:

Cancún is a tourist hotspot in Mexico with about 1,000 hotels and over six million tourists every year. The hotel industry, therefore, has significant regional and national importance as an employer and economic factor. Although the hotel industry is a major employer, this industry is not a driver for the development of high-quality jobs for highly qualified employees due to low average wages. This circumstance, together with the high level of local competition, has led to a great demand for skilled workers. At the same time, this has led to a staffing shortage, especially at the middle level, including receptionists and service personnel. Due 
to the existing demand, the hotel industry is participating in a government initiative aimed at improving VET within the legal framework of the 'Modelo Mexicano de Formación Dual (MMFD)' by intensifying cooperation between educational institutions and the industry. A central research question and problem of VET research arises precisely from this focus: How can cooperation between two institutions and their actors succeed if they pursue different goals based on their interests and functions (training versus profit)?

On the basis of a theoretical framework proposed by Billet et al. (2007), the authors of this article conducted qualitative interviews to examine the principles of successful cooperation. Their analysis focussed on the following three principles: building and maintaining shared purposes and goals, building and maintaining relations with partners and building and maintaining partnership governance and leadership.

\section{Macrosystem Level}

\section{Social representation of non-academic work in Mexico in the light of cultural artefacts by} Ute Clement, Paola García Fuentes, Stefan Gold, Claudia Hunink and Lydia Raesfeld:

This contribution is also focused on Mexico and is linked directly to the contribution of Vogelsang et al. (2021) at the exosystem level. The term 'non-academic work' was used in this article for a broad field of activities (e.g. agriculture or industrial activities) requiring competences not acquired at the university. Even though such non-academic work forms the backbone of any economy and society, it is often considered in Mexico (and in other countries) as something deficient and inferior, especially when compared to academic work. This perception is a historically and culturally shaped social construct that is very powerful and influences the education and employment systems equally.

Certainly, there is consensus in this general form of description. The difficulties arise as soon as deeper questions are asked (e.g. What exactly is the social representation of nonacademic work for (young) people in Mexico?). For their analysis, the authors used the theoretical framework model by Abric (1993), who distinguished between stable and rigid core elements and unstable and fluid peripheral elements. Social representations are shaped by human actions in artefacts and thus become visible; in turn, these artefacts shape social representations and thus become effective. This reciprocity between social representations and artefacts makes it possible to capture the social representations that are influenced by them via the analysis of artefacts. In analysing and presenting the results, the authors considered three categories in more detail: Competencies (e.g. Which knowledge does the working person show?), Habitus (e.g. What is the working person proud of?) and Working Conditions (e.g. Which context conditions are visible?). 
The following three articles are review studies considered as second-order research. Here, we refer to the definition of literature reviews as "systematic syntheses of previous work around a particular topic" (Card, 2010, p. 725).

\section{Review Study: European VET Policy}

Mapping research on European VET policy with a systematic literature review method: $A$ pilot study by Ianina Scheuch, Sandra Bohlinger, Anne Bieß and Hoang Long Nguyen:

European VET policy is a heterogeneous field of knowledge that is difficult to delineate. This article has two aims: (1) To test the extent to which the method of a systematic review is suitable for use in such a complex research field, and (2) to assess the application of the method to systematise and measure the field of knowledge, even if the results may not be conclusive. As a methodological framework, the authors used the approach of Gessler and Siemer (2020) with the following four phases: (1) Definition of the scope, (2) data selection, (3) data processing and (4) data reporting. The search criteria are deliberately narrow. In particular, the search is for a combination of 'VET' or 'vocational education and training' in combination with 'polic $c^{\star \prime}$ or other suitable terms (e.g., 'governance').

The authors worked with curated databases (e.g. Scopus) and found 70 articles in English for the period 2000-2020 after screening. Of these, 30 studies remained after performing another round of screening and controlling eligibility, thus building the grounding of the analysis. After a count (e.g. articles published per journal), a matrix was developed to group the existing articles in terms of topics and methods. Three major clusters were distinguished: (1) Governance in European VET policy at the EU-system level, (2) European VET policy and cross-country comparisons in the EU and (3) European VET policy implementation at the national level. Finally, the authors reflected on their experiences in applying the review method during the four phases of the review. The authors' critical review thus applies an interpretative scheme that captures the method in combination with the topic.

\section{Review Study: Transfer of VET}

Transfer in international vocational education and training research: A systematic literature review by Miriam Toepper, Olga Zlatkin-Troitschanskaia and Carla Kühling-Thees:

The authors conducted a systematic review to examine the topic 'transfer of VET' from one place to another, which can include, e.g., ideas, concepts, structures and practices. The search terms used were combined with the term 'transfer', such as 'policy transfer', 'educational transfer' or 'transfer of training'. This demonstrates the diversity in which the term is being used in research. With the additional aim of including the transfer of the German dual system abroad 
(e.g. the articles on Mexico in this special issue), the search terms 'German dual system' and 'dual apprenticeship' were also used.

The search yielded 230 German and English language studies published from 2010-2020. In addition to a database search, the 'snowball sampling technique' was also used. After abstract/ full-text screening and application of the inclusion criteria, 40 studies were included in the analysis. These 40 articles were systematically analysed using the following criteria: (1) Aim of the study, (2) method, (3) sample, (4) countries involved and (5) reference. From these 40 studies, six studies were of a theoretical-conceptual nature. However, the methodological basis of the other empirical studies was not always ascertainable. For example, the research methods and samples were not always precisely described. The analysis was thus condensed with regard to the 'key challenges in VET transfer' and 'key success factors in VET transfer'. The authors concluded by reflecting on the limitations and formulating implications for future research. Notably, most studies are based on recipient countries or companies, which is why the authors recommend a greater focus on comparative transfer studies with different countries in the future.

\section{Review Study: VET Research}

Scoping review on research at the boundary between learning and working: A bibliometric mapping analysis by Michael Gessler, Christof Nägele and Barbara Stalder:

Large-scale scoping reviews or mapping reviews are still rare in VET research. Nevertheless, the first few systematic knowledge mapping approaches have already been introduced. For example, Bezerra et al. (2020) conducted a worldwide mapping of work-based learning research (period covered: All years, $\mathrm{N}=410$ ). The current paper, meanwhile, has an even broader focus: VET research. Thus, 'work-based learning' was included as a search term. Alternative terms (e.g. 'skill formation' or 'technical education') were also considered because VET is a widely used but sometimes criticised and, therefore, sometimes substituted term (Dougherty \& Lombardi, 2016).

The study deals with the research question: How has VET research evolved in the last decade? Within this broad scope, the authors concentrated on four aspects: the actors, the knowledge base, the major themes and the evolution of the themes in time. The search was limited to English-language and peer-reviewed articles published between 2011-2020. Finally, the authors obtained 5,474 articles, which they subsequently considered in the analysis. This study used bibliometric analysis, a technique that has increasingly been used as a tool and basis for monitoring the research content and performance of scientific disciplines. Various tools were used for different purposes, such as biblioshiny for bibliometrix, an R-tool for science mapping analysis (Aria \& Cuccurullo, 2017) to perform descriptive bibliometric analysis and the software SciMat for mapping analysis within a longitudinal framework to identify major themes and the evolution of the themes in time (Cobo et al., 2012). 


\section{Conclusion}

The model of the 'triadic conception of purposes in comparative VET research' (Evans 2020) represents a heuristic for describing the purposes of international VET research. In this model, two strands of research are linked: (i) International and intercultural comparative VET research, which focusses on mutual learning and exchange along the dimensions of similarity and difference, and (ii) development studies, which focus on a contextualised understanding of change and pursue concrete development goals, such as poverty reduction ('improvement'). These approaches have in common that they are based on the importance of understanding and communication as necessary conditions. Ultimately, international VET research differs from other fields of enquiry in the way it achieves 'criticality', which is at the centre of the triadic purpose. The triadic conception of the purposes of international comparative VET research is illustrated in Figure 2.

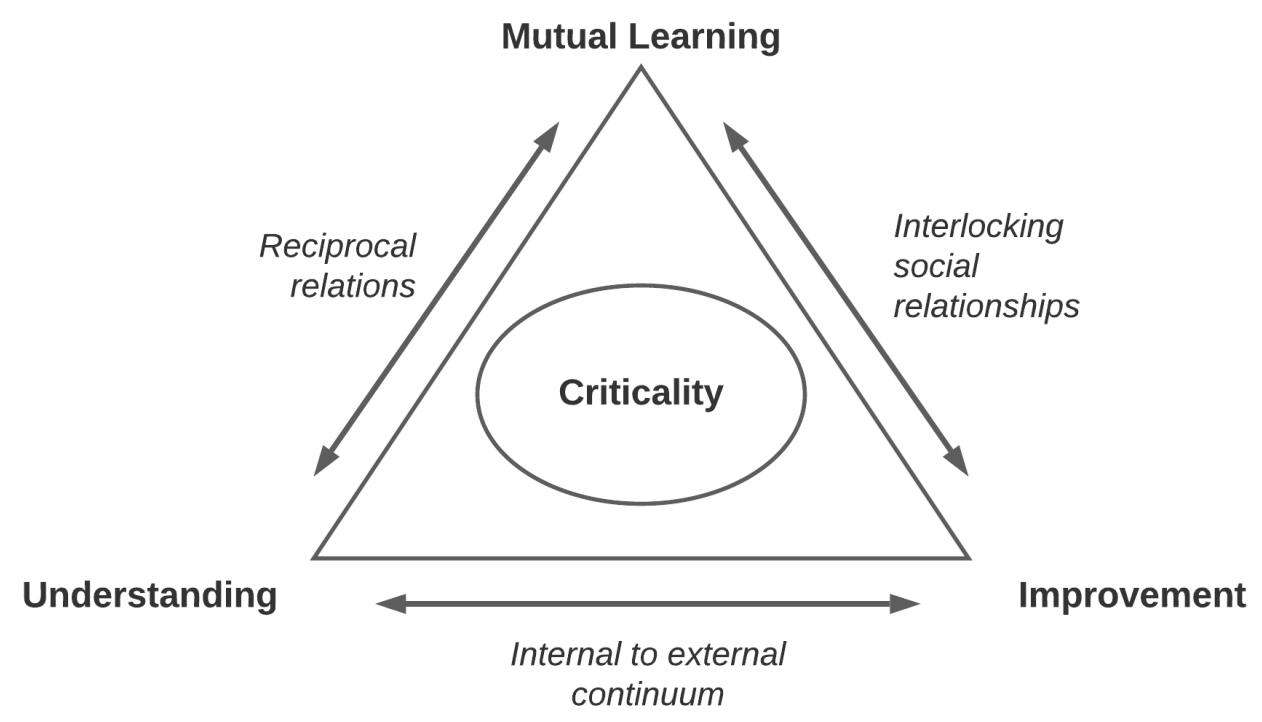

Figure 2: Triadic Conception of Purposes, Source: Evans (2020, p. 16)

While German international VET cooperation lacked any form of evaluation and reflection until the 1990s (see Introduction), from 1990-2010, international VET cooperation lacked something even more fundamental: Attention. Since the 2010s, political attention has returned, and with this turnaround, research funding has also begun again (with the first projects starting in 2019), and with research, criticality has finally returned. Criticality means countering uncritical assumptions of unilinear development perspectives and dominant discourses. It is the value of international VET research that lies precisely in this tension between existing interests and practices, as exemplarily illustrated in this special issue. 


\section{Acknowledgements}

The special issue and its contributions were funded by the German Federal Ministry of Education and Research (BMBF) as part of the program "Research on the Internationalisation of Vocational Education and Training". We are grateful for the sponsorship and especially thank all authors and reviewers warmly for their contribution to this special issue.

\section{References}

Abric, J. C. (1993). Central system, peripheral system: Their functions and roles in the dynamics of social representations. Papers on Social Representations, 2(2), 75-78. https://psr.iscte-iul.pt/index. $\mathrm{php/PSR/article/view/126}$

Aria, M., \& Cuccurullo, C. (2017). Bibliometrix: An R-tool for comprehensive science mapping analysis. Journal of Informetrics, 11(4), 959-975. https://doi.org/10.1016/j.joi.2017.08.007

Billett, S., Ovens, C., Clemans, A., \& Seddon, T. (2007). Collaborative working and contested practices: Forming, developing and sustaining social partnerships in education. Journal of Education Policy, 22(6), 637-656.

BMBF Bundesinstitut für Bildung und Forschung. (2013). Strategiepapier der Bundesregierung zur internationalen Berufsbildungszusammenarbeit aus einer Hand. Deutscher Bundestag. https://www. govet.international/dokumente/pdf/ab12govet_Bundesanzeiger_Strategiepapier_der_Bundesregierung_zur_internationalen_Berufsbildungszusammenarbeit.pdf

BMBF Bundesinstitut für Bildung und Forschung. (2017). Announcement regulations governing funding for research on the internationalization of vocational education and training (VET). https:// www.berufsbildung-international.de/files/BEK_IBBF_eng.pdf

BMBF Bundesinstitut für Bildung und Forschung. (2019). Strategie der Bundesregierung zur internationalen Berufsbildungszusammenarbeit. https://www.bmbf.de/bmbf/shareddocs/downloads/ files/137_19_strategie_bundesregierung.pdf?_blob=publicationFile\&v=1

Bronfenbrenner, U. (1979). The ecology of human development: Experiments by nature and design. Havard University Press.

Bronfenbrenner, U., \& Evans, G. W. (2000). Developmental science in the 21st century: Emerging questions, theoretical models, research designs and empirical findings. Social Development, 9(1), 115-125. https://doi.org/10.1111/1467-9507.00114

Bronfenbrenner, U., \& Morris, P. A. (2006). The bioecological model of human development. In R. M. Lerner \& W. Damon (Eds.), Handbook of child psychology: Theoretical models of human development (pp. 793-828). Wiley. https://doi.org/10.1002/9780470147658.chpsy0114

Card, N. A. (2010). Literature review. In N. J. Salkind (Ed.), Encyclopedia of Research Design (pp. 725 728). Sage.

Cobo, M. J., López-Herrera, A. G., Herrera-Viedma, E., \& Herrera, F. (2012). SciMAT: A new science mapping analysis software tool. Journal of the American Society for Information Science and Technology, 63(8), 1609-1630. https://doi.org/10.1002/asi.22688 
Dougherty, S. M., \& Lombardi, A. R. (2016). From vocational education to career readiness: The ongoing work of linking education and the labor market. Review of Research in Education, 40(1), 326-355. https://doi.org/10.3102/0091732X16678602

Edel, M. (2020). Build4Skills, TVET, and infrastructure - An innovative initiative. In B. Panth \& R. Maclean (Eds.), Anticipating and preparing for emerging skills and jobs (pp. 291-296). Springer. https://doi.org/10.1007/978-981-15-7018-6_35

Evans, K. (2020). Comparative vocational education and training research: What purposes does it serve? In M. Pilz \& J. Li (Eds.), Comparative vocational education research: Enduring challenges and new ways forward (pp. 3-19). Springer. https://doi.org/10.1007/978-3-658-29924-8_1

Gessler, M. (2017). Educational transfer as transformation: A case study about the emergence and implementation of dual apprenticeship structures in a German automotive transplant in the United States. Vocations and Learning, 10(1), 71-99. https://doi.org/10.1007/s12186-016-9161-8

Gessler, M., \& Siemer, C. (2020). Umbrella review: Methodological review of reviews published in peer-reviewed journals with a substantial focus on vocational education and training research. International Journal for Research in Vocational Education and Training, 7(1), 91-125. https://doi. org/10.13152/IJRVET.7.1.5

Kell, A. (1990). Lernen und Arbeiten. Zu einem berufspädagogischen Thema und seiner Forschungslage. Berufsbildung in Wissenschaft und Praxis, 19(6), 15-20.

Kell, A. (1995). Organisation, Recht und Finanzierung der Berufsbildung. In R. Arnold, \& A. Lipsmeier (Eds.), Handbuch der Berufsbildung (pp. 369-397). Leske + Budrich.

Lange, S. (2019). Die Berufsausbildungseingangsphase: Anforderungen an Auszubildende und ihre Bewältigungsstrategien am Beispiel des Kfz-Mechatronikerhandwerks. wbv Media GmbH \& Co. KG. https://doi.org/10.3278/6004720w

OECD Organisation for Economic Co-operation and Development. (2010). Learning for jobs: OECD reviews of vocational education and training. Paris: OECD.

Stockmann, R. (1992). Die Nachhaltigkeit von Entwicklungsprojekten: Eine Methode zur Evaluierung am Beispiel von Berufsbildungsprojekten. Springer. https://link.springer.com/book/10.1007\% 2F978-3-322-93597-7

Streeck, W. (2011). Skills and politics: General and specific. MPIfG Discussion Paper, 11(1). https:// www.mpifg.de/pu/mpifg_dp/dp11-1.pdf

Sturing, L., Biemans, H. J. A., Mulder, M., \& De Bruijn, E. (2011). The nature of study programmes in vocational education: Evaluation of the model for comprehensive competence-based vocational education in the Netherlands. Vocations and Learning, 4(3), 191-210. https://doi.org/10.1007/ s12186-011-9059-4

Van den Akker, J., Fasoglio, D., \& Mulder, H. (2010). A curriculum perspective on plurilingual education. Council of Europe. https://rm.coe.int/16805a1e57

Wolf, S. (2009). Berufsbildung und Kultur - Ein Beitrag zur Theorie der Berufsbildung in der Entwicklungszusammenarbeit. TU Berlin. https://depositonce.tu-berlin.de/handle/11303/2421

Zlatkin-Troitschanskaia, O. (2005). Dynamik und Stabilität in Berufsbildungssystemen - Eine theoretische und empirische Untersuchung von Transformationsprozessen am Beispiel Bulgariens und Litauens. Peter Lang. 


\section{Biographical Notes}

Michael Gessler, Dr phil., Dr h.c., is Full Professor of Technical and Vocational Education and Training at the Institute Technology and Education (ITB), University of Bremen, Germany. His research focus is on innovations and transfer of innovations in vocational education and training.

Sandra Bohlinger, Dr phil., is Full Professor of Adult Education at the Institute of Vocational Education and Training, Faculty of Education, Technical University Dresden. Her research focus is on labour market-related training and comparative education.

Dr Olga Zlatkin-Troitschanskaia is Full Professour of Business and Economics Education at Johannes Gutenberg University Mainz (JGU), Germany. Her research focuses on modeling and measuring student knowledge, skill development and learning outcomes in vocational and higher education at both national and international level. 